\title{
Interaksi Tanaman Kacang Tanah (Arachishypogeae) dalam Agroforestri Interaction Of Peanuts (Arachis hypogeae) In Agroforestri
}

\section{Fahruni}

\author{
Dosen Program Studi Kehutanan Fakultas Pertanian dan Kehutanan \\ Universitas Muhammadiyah Palangkaraya \\ Email : fahruni1974@gmail.com
}

\begin{abstract}
Nutrient availability in the forest soils is effected by forest degradation and deforestation as forest conversion. Peanut (Arachishypogeae) is included LeguminalesOrdo and able to supply nutrient from the plant parts. As intercrops in agroforestry patterns, peanuts provide interaction for the surrounding soil and plants. The purpose of this research is to know the interaction of peanut plants on nutrient availability and on the growth of rubber plant (HeveabrasiliensisMuell, Arg.) on agroforestry pattern. This research was conducted at the Banjarbaru through the observation of rubber plant growth and soil analysis. Research result show that peanuts can increase the availability of nutrients in the soil. The $\mathrm{N}$ element increases from $0.16 \%$ to $0.45 \%$, thereby stimulating vegetative growth (green) such as leaves. The P element increases from $5.57 \mathrm{mg} / 100 \mathrm{gr}$ to $8.93 \mathrm{mg} / 100 \mathrm{gr}$, the $\mathrm{K}$ element increases from $15.87 \mathrm{mg} / 100 \mathrm{gr}$ to $41.50 \mathrm{mg} / 100 \mathrm{gr}$, and organic $\mathrm{C}$ increased from $0.83 \%$ to $1.55 \%$. The interaction of peanut crops as intercropping plants was able to give high impact to height of rubber plant, namely $77.68 \mathrm{~cm}$. The impact on the growth of rubber plant diameter also increased by $0.59 \mathrm{~cm}$ compared to only the rubber pattern of $0.28 \mathrm{~cm}$.
\end{abstract}

Keywords: Interaction, peanuts, rubber growth, agroforestry.

\begin{abstract}
Abstrak
Ketersediaan unsur hara dalam tanah hutan dipengaruhi oleh kerusakan hutan dan deforestasi seperti alih fungsi hutan. Upaya menjaga kecukupan hara tanah dapat diusahakan melalui penerapan pola agroforestry. Tanaman kacang tanah (Arachishypogeae )termasuk dalam ordo Leguminales dan mampu mensuplai unsur hara dari bagian tanamannya. Sebagai tanaman sela dalam pola agroforestri, kacang tanah memberikan interaksi bagi tanah dan tanaman di sekitarnya.Tujuan penelitian ini adalah mengetahui interaksi tanaman kacang tanah terhadap ketersediaan unsur hara dan terhadap pertumbuhan tanaman karet (Heveabrasiliensis Muell, Arg.) pada pola agroforestri. Penelitian ini dilakukan dengan pengamatan pertumbuhan tanaman karet dan analisis tanah yang dilakukan sebelum dan sesudah penelitian. Hasil penelitian menunjukan bahwa kacang tanah mampu meningkatkan ketersediaan unsur hara di dalam tanah. Unsur $\mathrm{N}$ meningkat dari $0,16 \%$ menjadi $0,45 \%$, sehingga merangsang pertumbuhan vegetatif (warna hijau) seperti daun. Unsur P meningkat dari $5,57 \mathrm{mg} / 100$ gr menjadi $8,93 \mathrm{mg} / 100 \mathrm{gr}$, Unsur K yaitu dari $15,87 \mathrm{mg} / 100$ gr menjadi $41,50 \mathrm{mg} / 100 \mathrm{gr}$, dan $\mathrm{C}$ organik meningkat dari $0,83 \%$ menjadi $1,55 \%$. Interaksi tanaman kacang tanah sebagai tanaman sela mampu memberikan dampak pertambahan tinggi tanaman karet yaitu sebesar 77,68 cm. Dampak terhadap pertumbuhan diameter tanaman karet juga mengalami peningkatan pertambahan sebesar $0,59 \mathrm{~cm}$ dibandingkan pada hanya pola karet saja yaitu $0,28 \mathrm{~cm}$.
\end{abstract}

Kata kunci : Interaksi, kacang tanah, pertumbuhan karet, agroforestry. 


\section{PENDAHULUAN}

Alih fungsi kawasan hutan membawa dampak global terhadap suhu dan kualitas tanah. Suhu dalam skala mikro akan mengalami perubahan dan sangat terasa secara signifikan (Oksana, et.al, 2012). Perubahan ini sebagai akibat dari pembukaan area yang menyebabkan radiasi matahari lebih banyak terpapar sehingga menimbulkan kenaikan temperatur. Peningkatan panas dapat merubah komposisi mikribiologi tanah yang juga mempengaruhi kesuburan tanah.

Dampak penurunan kualitas tanah menyebabkan jenis tertentu saja yang dapat bertahan tumbuh pada daerah tersebut. Agar tanaman dapat tumbuh normal diperlukan kualitas tanah yang baik sebagai media tanam yang menyediakan unsur hara yang mencukupi. Dalam rangka menjaga kualitas tanah, perlu suatu usaha agar tanaman dapat tumbuh pada areal pembukaan hutan. Tidak saja tanaman semusim, tetapi juga jenis tanaman tahunan atau tanaman kehutanan, dimana fungsi tanaman dapat menjaga kualitas tanah dan iklim mikro di kawasan tersebut.

Upaya mempertahankan kualitas tanah dapat dilakukan melalui pemanfaatan lahan yang bijaksana. Agroforestry sebagai salah satu solusi pemanfaatan lahan yang tetap memelihara kesuburan tanah karena dapat memanfaatkan lahan melalui pengkombinasian tanaman kehutanan dengan pertanian dan/atau peternakan pada suatu lahan secara bergiliran atau bergantian.

Kacang tanah (Arachishypogeae) merupakan tanaman yang kaya akan unsur nitrogen $(\mathrm{N})$. Mulai dari bagian akar, batang, daun bahkan pucuknya mempunyai kandungan $\mathrm{N}$ yang mampu dimanfaatkan oleh tanaman lain. Sistem tumpang sari dalam agroforestry memberikan tambahan unsur hara yang lebih bagi tanaman kehutanan ketika disandingkan dengan tanaman kacang ini.

Penelitian ini dimaksudkan untuk melakukan kajian sistem agroforestry antara kacang tanah sebagai tanaman semusim dan tanaman karet sebagai tanaman tahunan.

Pola seperti ini diharapkan mampu menyediakan informasi penting dalam rangka pengusahaan lahan oleh pihak pemerintah atau pun stakeholder lainnya terutama pihak masyarakat. Penelitian ini bertujuan mengetahui ketersediaan unsurhara ; Nitrogen $(\mathrm{N})$, Fosfor $(\mathrm{P})$, dan Kalium (K) dalam tanah yang diterapkan pola agroforestry. 


\section{METODOLOGI}

Penelitian ini dilaksanakan dikebun tanaman karet (Heveabrasiliensis Muell, Arg.) milikpetani yang telah berumur 6 bulan. Kegiatan penelitian meliputi ; persiapan, pengumpulan data primer, dan sekunder, pengolahan data hingga penyusunan laporan.

Bahan yang diperlukan dalam penelitian ini adalah tanaman kacang tanah serta tanaman karet yang berumur 6 bulan. Sedangkan peralatan yang digunakan adalah cangkul, parang, ring sampel tanah, kantong plastik, meteran, kamera, timbangan, alat tulis menulis, laptop. Variabel penelitian adalah kandungan $\mathrm{N}$, $\mathrm{P}, \mathrm{K}$ dan $\mathrm{C}$ organic dalam tanah serta tinggi dan diameter tanaman karet.

Pada plot penelitian, dilaksanakan pembukaan lahan dan pengolahan tanah sela-sela tanaman karet yang telah ditanam. Pupuk kandang kotoran ayam sebagai pupuk dasar diberikan setelah selesai pengolahan tanah dan di biarkan selama 1 minggu.

Penanaman tanaman sela kacang tanah dilaksanakan pada plot yang telah ditentukan dengan jarak tanam sesuai metode. Selama penelitian berlangsung dilakukan pembersihan gulma di sekitar tanaman sela dan tanaman pokok sehingga pertumbuhan tanaman dapat berjalan normal.

Dalam jangka waktu 100 hari penanaman, kacang tanah siap panen. Selanjutnya setelah pemanenan dilaksanakan, segera dilakukan pengambilan sampel tanah pada obyek penelitianya itu pada lahan agroforestry kombinasi karet dan kacang tanah.

Penelitian dimulai dengan (1) pengambilan sampel tanah pada lokasi penelitian secara purposive sampling. (2) pengambilan sampel tanah pada lapisan kedalaman $0 \quad-15 \mathrm{~cm}$. (3) Sampel tanah yang telah di ambil selanjutnya melakukan analisis di laboratorium ilmu tanah Fakultas Pertanian Universitas Lambung Mangkurat, untuk mengetahui kandungan unsur hara makro $\mathrm{N}, \mathrm{P}$ dan $\mathrm{K}$ dan $\mathrm{C}$ organik. (4) Pengambilan sampel pertama di laksanakan pada saat sebelum penanaman tanaman sela yaitu kacang tanah (Arachis hypogeae L.). Selanjutnya pada pengambilan sampel kedua dilaksanakan setelah proses pertumbuhan dan pemanenan tanaman kacang tanah (Arachis hypogeae L.). (5) Melakukan analisis di laboratorium kandungan unsur hara makro N, P dan $\mathrm{K}$ dan $\mathrm{C}$ organik. (6) melakukan analisis pertumbuhan tanaman karet. 
HASIL DAN PEMBAHASAN

\section{A. Interaksi Tanaman Kacang Tanah}

Kualitas tanah pada pola agroforestri karet dapat dilihat dari ketersediaan unsure hara makro yang menjadi obyek penelitian sebelum masa penanaman tanaman sela kacang tanah adalah sebagaimana pada tabel berikut:

Tabel 1. Hasil Analisis Tanah Sebelum Penelitian

\begin{tabular}{|l|l|l|l|}
\hline No. & Unsur Hara & Ketersediaan & Kriteria*) $^{*}$ \\
\hline 1 & $\mathrm{~N}(\%)$ & 0,16 & Rendah \\
\hline 2 & $\mathrm{P}_{2} \mathrm{O}_{5}(\mathrm{mg} / 100 \mathrm{gr})$ & 5,57 & $\begin{array}{l}\text { Sangat } \\
\text { Rendah }\end{array}$ \\
\hline 3 & $\mathrm{~K}_{2} \mathrm{O}(\mathrm{mg} / 100 \mathrm{gr})$ & 15,87 & Rendah \\
\hline 4 & C organik (\%) & 0,83 & $\begin{array}{l}\text { Sangat } \\
\text { Rendah }\end{array}$ \\
\hline
\end{tabular}

Sumber: data primer hasil analisis laboratorium

*) berdasarkan kriteria penilaian sifat kimia tanah

BerdasarkanTabel 1 di atas, unsur $\mathrm{N}$ memiliki kriteria rendah yaitu $0,16 \%$, terlebih unsur yang P ketersediaannya 5,57 $\mathrm{mg} / 100 \mathrm{gr}$ memiliki kriteria sangat rendah.Sedangkan unsur $\mathrm{K}$ dengan ketersediaan 15,87 $\mathrm{mg} / 100 \mathrm{gr}$ memiliki kriteria rendah, dan $\mathrm{C}$ organik dengan ketersediaan $0,83 \%$ memiliki kriteria sangat rendah.

Pada saat penelitian berlangsung bulan basah, dimana menurut data curah hujan 10 tahun terakhir, terdapat 9 bulan basah. Sedangkan jenis tanah yang terdapat pada lokasi penelitian adalah podsolik dengan tekstur lempung berpasir yang memerlukan tambahan unsur hara baik berupa humus ataupun pupuk organik dan anorganik.

Adapun setelah dilaksanakannya penanaman kacang tanah pada agroforestri, dilakukan analisis tanah terhadap kandungan unsur hara makro dengan kriteria penilaian hasil analisis tanah di lahan agroforestri karet pada saat pra penelitian dan pasca penelitian. Sebagaimana tabel berikut. 
Tabel 2. Hasil Penilaian dari Analisis Tanah di Lahan Agroforestri Karet

\begin{tabular}{|l|l|l|l|l|l|}
\hline No. & Unsur Hara & $\begin{array}{l}\text { Ketersediaan } \\
\text { Pra } \\
\text { Penelitian }\end{array}$ & Kriteria*) & $\begin{array}{l}\text { Ketersediaan } \\
\text { Pasca } \\
\text { Penelitian }\end{array}$ & Kriteria*) \\
\hline 1 & $\mathrm{~N}(\%)$ & 0,16 & Rendah & 0,45 & Sedang \\
\hline 2 & $\begin{array}{l}\mathrm{P}_{2} \mathrm{O}_{5} \\
(\mathrm{mg} / 100 \mathrm{gr})\end{array}$ & 5,57 & $\begin{array}{l}\text { Sangat } \\
\text { Rendah }\end{array}$ & 8,93 & $\begin{array}{l}\text { Sangat } \\
\text { Rendah }\end{array}$ \\
\hline 3 & $\mathrm{~K}_{2} \mathrm{O}(\mathrm{mg} / 100 \mathrm{gr})$ & 15,87 & Rendah & 41,50 & Tinggi \\
\hline 4 & C organik (\%) & 0,83 & $\begin{array}{l}\text { Sangat } \\
\text { Rendah }\end{array}$ & 1,55 & Rendah \\
\hline
\end{tabular}

Sumber: data primer hasil analisis laboratorium

*) berdasarkan kriteria penilaian sifat kimia tanah

Pada tabel di atas terlihat adanya peningkatan ketersediaan unsur hara setelah adanya kegiatan agroforestri di lahan perkebunan karet. Melalui penanaman tanaman sela berupa kacang tanah, terlihat adanya peningkatan unsur $\mathrm{N}$ dari 0,16 (rendah) menjadi 0,45 (sedang), sehingga merangsang pertumbuhan vegetatif (warna hijau) seperti daun.
Demikian pula pada unsur $\mathrm{P}$ meningkat dari 5,57 (sangat rendah) menjadi 8,93 (sangat rendah) meskipun masih pada kriteria sangat rendah, namun peningkatan ini dapat berpengruh terhadap pembungaan, pembuahan, pertumbuhan akar, pembentukan biji dan pembelahan sel. Gambaran kandungan hara tanah dapat dilihat pada Gambar 1.

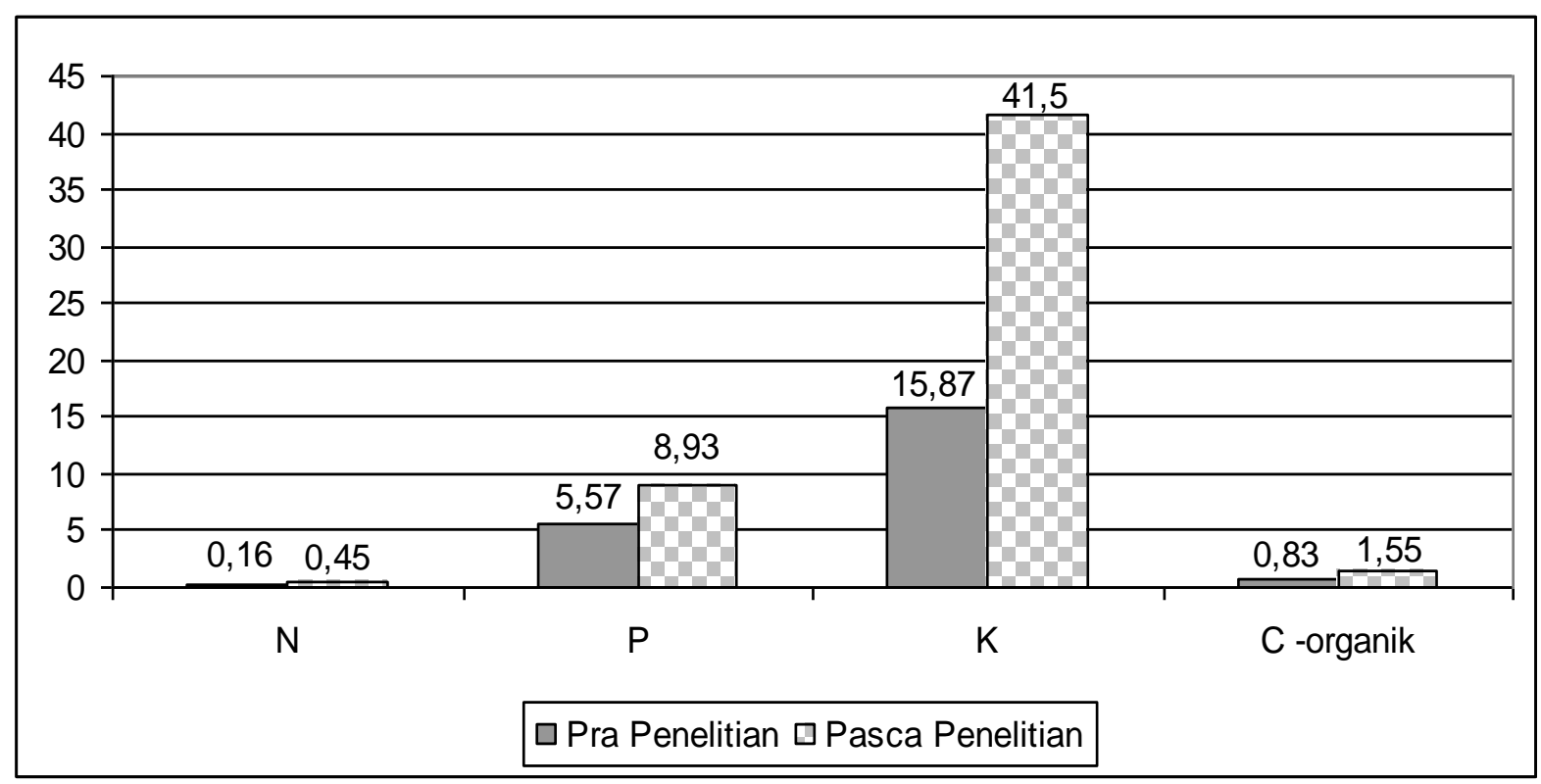

Gambar 1. Diagram Hasil Analisis Tanah di Lokasi Penelitian 
Keberadaan kacang tanah pada mampu memperbaiki kandungan unsure hara tanah. Hal ini disebabkan kacang tanah termasuk kelompok tanaman Leguminales yang mampu mengikat $\mathrm{N}$ dari udara. Kacang tanah yang merupakan tanaman semusim juga memerlukan perawatan yang intensif agar diperoleh hasil yang baik pada saat panen. Pengaruh perawatan tanaman kacang tanah ini akan berdampak positif pada sifat fisik maupun kimia tanah. Sisa-sisa tanaman kacang tanah yang telah terdekomposisi akan memberikan tambahan unsure hara pada tanah, sehingg akan disi tanah relative menjadi semakin baik.

Pada Tabel 2 terlihat adanya peningkatan ketersediaan unsur hara setelah adanya kegiatan agroforestri di lahan perkebunan karet. Terlihat bahwa unsur $\mathrm{N}$ meningkat dari 0,16 (rendah) menjadi $\quad 0,45 \quad$ (sedang), sehingga merangsang pertumbuhan vegetatif (warna hijau) seperti daun. Demikian pula pada unsur $\mathrm{P}$ meningkat dari 5,57 (sangat rendah) menjadi 8,93 (sangat rendah) meskipun masih pada kriteria sangat rendah, namun peningkatan ini dapat berpengruh terhadap pembungaan, pembuahan, pertumbuhan akar, pembentukan biji dan pembelahan sel.
Pada Gambar 1, peningkatan signifikan terlihat pada unsur $\mathrm{K}$ yaitu dari 15,87 (rendah) menjadi 41,50 (tinggi) berakibat pada proses fotosintesa dan meningkatkan daya tanah/kekebalan tanaman terhadap hama dan penyakit. Namun pada unsur $\mathrm{C}$ organik hanya meningkat sedikit meskipun masih dalam kriteria rendah yaitu dari 0,83 (sangat rendah) menjadi 1,55 (rendah). Peningkatan ketersediaan unsur hara ini tentunya membawa dampak positif terhadap pertumbuhan tanaman karet yang tumbuh dalam areal agroforestri tersebut.

Berdasarkan pengamatan di lapangan bahwa tanaman sela yang ditanam pada penelitian ini tidak terdapat serangan hama, sehngga bila dihubungkan dengan ketersediaan unsur $\mathrm{K}$ setelah penelitian meningkat menjadi $41,5 \mathrm{mg} / 100 \mathrm{gr}$. Berdasarkan hal tersebut dapat dipastikan bahwa unsur $\mathrm{K}$ sedikit yang diserap tanaman dan digunakan untuk proses fotosintesis, dan selebihnya tidak diserap untuk peningkatan kekebalan karena tidak adanya serangan hama/penyakit terhadap tanaman disekitarnya.

\section{B. Pertumbuhan Tanaman Karet}

Pada sistem agroforestry, tanaman karet mampu mencapai tinggi sebesar $77,68 \mathrm{~cm}$ sedangkan pada system tanaman 
karet murni hanya memberikan tinggi sebesar 47,72 cm (Gambar 2). Sedangkan pada pertumbuhan diameter tanaman karet, sistem agroforestry mampu memberikan pertumbuhan diameter sebesar $0,59 \mathrm{~cm}$ sementara itu system tanaman karet murni hanya sebesar 0,28 cm (Gambar 3).

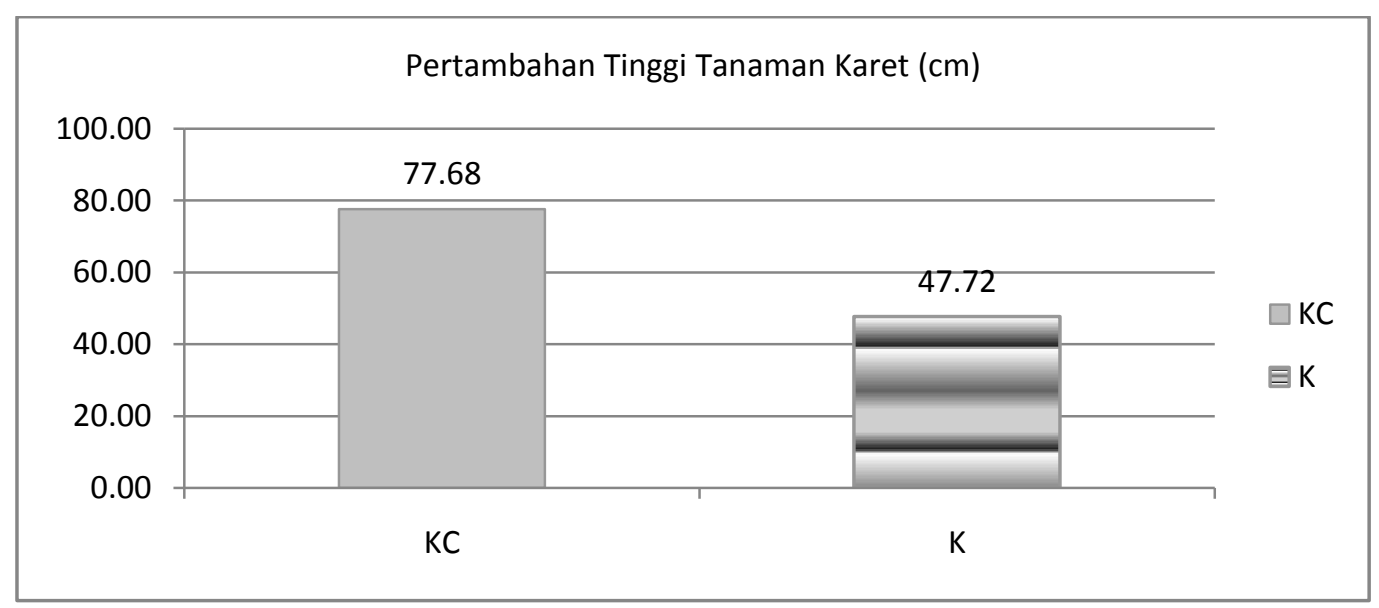

Gambar 2. Pertambahan Tinggi Tanaman Karet

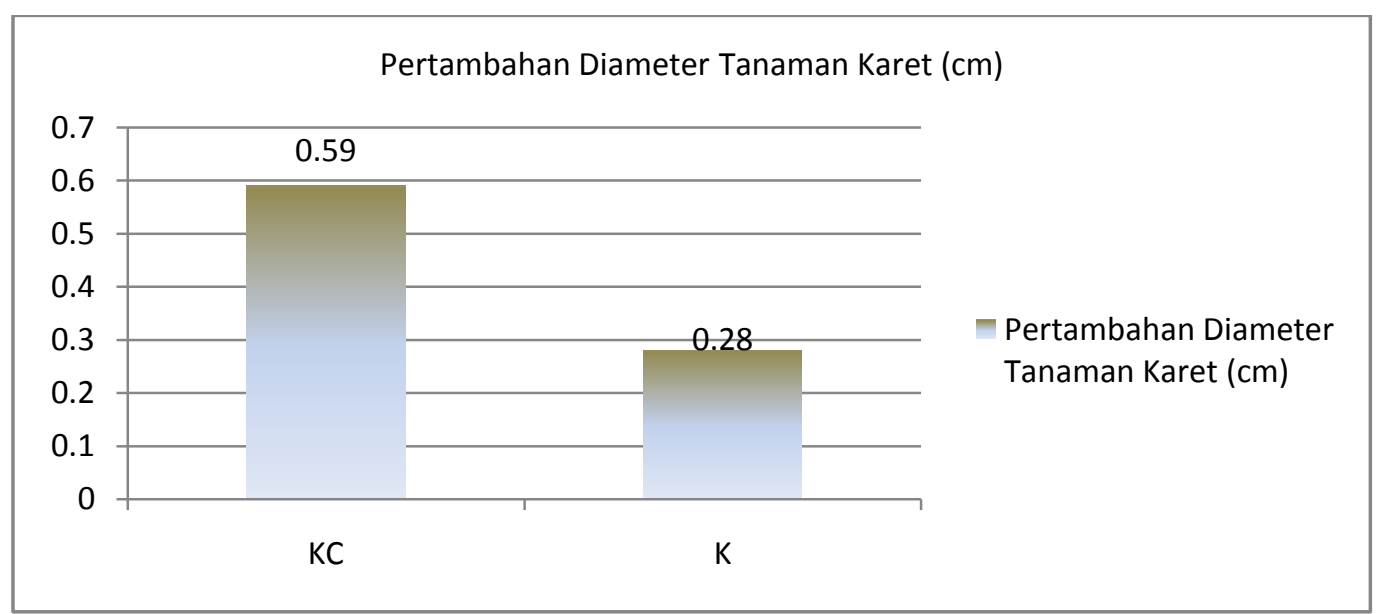

Gambar 3. Grafik Pertambahan Diameter Tanaman Karet

Pengusahaan tanaman kacang tanah pada pola agroforestri membawa pengaruh yang positif terhadap pertumbuhan tanaman pokok yaitu karet (Hevea brasiliensis Muell. Arg.). Berdasarkan penelitian ini tanaman karet mempunyai pertumbuhan tinggi yang lebih baik ketika ditanam dengan pola agroforestry, yaitu pada sela sela tanaman karet ditanami kacang tanah. Hal ini sebabkan akar tanaman kacang tanah dapat mengikat nitrogen dari udara sehingga dapat menambahan kandungan unsure hara ini. Sisa-sisa tanaman kacang tanah yang telah terdekomposisi juga mampu memperbaiki sifat fisik dan kimia tanah. Tanah menjadi 
lembur gembur dan kandungan bahan organic relative bertambah, sehingga memberikan tempat tumbuh dan tambahan unsure hara bagi tanaman karet. Berdasarkan hasil penelitian, system agroforestry mampu meningkatkan pertumbuhan tinggi tanaman karet disbanding pada tanaman karet murni (tanpa adanya kacang tanah). Pada Gambar 2 terlihat bahwa tanaman karet pada sistem agroforestry, yaitu tanaman karet dengan diberi tanaman sela berupa kacang tanah, memberikan pertambahan tinggi yang lebih baik disbanding tanaman karet murni, yaitu tanaman karet tanpa diberi tanaman sela kacang tanah.

Peningkatan pertumbuhan tinggi tanaman karet merupakan peran positif tanaman sela (kacang tanah). Keunggulan sistem agroforestry dalam meningkatkan pertumbuhan tanaman tahunan juga diungkapkan oleh Hairiyah dkk (2002) yang mengatakan bahwa tanaman semusim berkontribusi positif terhadap peningkatan pertumbuhan tanaman tahunan pada pola agroforestry. De Foresta dkk (2000) juga menyebutkan bahwa tanaman semusim mampu mengoptimalkan pemanfaatan ruang tumbuh sehingga produktivitas lahan menjadi semakin tinggi.

\section{SIMPULAN DAN SARAN}

\section{Simpulan}

Menurut hasil penelitian, kesimpulan yang dapat diambil adalah sebagai berikut :

1. Interaksi tanaman kacang tanah dalam agroforestri memberikan hasil positif terhadap peningkatan ketersedian unsurhara di dalam tanah.

2. Penanaman kacang tanah sebagai tanaman sela mampu memberikan dampak pertambahan tinggi tanaman karet yaitu sebesar $77,68 \mathrm{~cm}$.

3. Dampak terhadap pertumbuhan diameter tanaman karet juga mengalami peningkatan pertambahan sebesar $0,59 \mathrm{~cm}$ dibandingkan pada hanya pola karet saja yaitu $0,28 \mathrm{~cm}$.

4. Ketersediaan unsure hara dalam agroforestri dapat disuplai melalui penanaman tanaman sela berupa kacang tanah.

\section{Saran}

Hasil yang positif dari interaksi tanaman kacang tanah dapat menjamin ketersediaan unsur hara secara ekologi, juga secara ekonomi dan sosial bagi petani agroforestri.Untuk itu perlu tindak lanjut pemanfaatan lahan pola agroforestri seperti ini. 


\section{DAFTAR PUSTAKA}

Budi, Wibawa G, Ilahang, Akiefnawati R, Joshi L, Penot E, Janudianto. 2008. Panduan Pembangunan Kebun Wanatani Berbasis Karet Klonal (A manual for Rubber Agroforestry SystemRAS). Bogor. World Agroforestry Centre (ICRAF) SEA Regional Office, Indonesia.

De Foresta. H, A Kusworo, G Michon dan WA Djatmiko. 2000. Ketika Kebun Berupa Hutan - Agroforest khas Indonesia Sumbangan masyarakat bagi pembangunan berkelanjutan. International Centre for Research in Agroforestry, Bogor, Indonesia; Institute de Recherch pour Developpement, France; dan Ford Foundation, Jakarta, Indonesia.

Deptan.2000. Paket Teknologi Anjuran Budidaya Kacang Tanah Di Lahan Kering. DepartemenPertanian. http://www.pustakadeptan.go.id/agritek/ntbr0105.pdf

Habibi. 2005. Evaluasi Keberhasilan Wanatani Kelompok Tani Hutan Di KRPH Gunung Sarib KPH Glenmore KPH Banyuwangi Barat. Tesis. Universitas Muhammadiyah Malang. http://digilib.umm.ac.id/habibi00743263

Kurniatun Hairiah, M.V. Noordwijk dan D. Suprayogo, 2002. Interaksi Antara Pohon - Tanah - Tanaman Semusim: Kunci Keberhasilan Atau Kegagalan Dalam Sistem Agroforestri. World Agroforestry Centre (ICRAF) Southeast Asia. Bogor.

Hanafiah, K.A. 2005. Rancangan Percobaan, Teori dan Aplikasi, Edisi Ketiga. Fakultas Pertanian Universitas Sriwijaya Palembang. PT Raja Grafinda Persada, Jakarta.
Hardjowigeno,S. 1993. Klasifikasi Tanah dan Pedogenesis. Akademi Pressindo. Jakarta.

ICRAF. 2005. Sistem Wanatani Berbasis Karet. World Agroforestry Centre (ICRAF) Southeast Asia. Bogor.

Oksana, Irfan.M. , Huda, M.U., 2012. PengaruhAlihFungsiLahanHutanMenjad i Perkebunan KelapaSawitTerhadapSifat Kimia Tanah. JurnalAgroteknologi, Vol. 3 No. 1, Agustus 2012: 29-34.

Ristek. 2000. Kacang Tanah ( Arachis hypogeae L.). Kantor Deputi Menegristek Bidang Pendayagunaan dan Pemasyarakatan Ilmu Pengetahuan dan Teknologi.

http://www.warintek.ristek.go.id/pertani an/kacang_tanah.pdf

Rosyid. M.J. 2006. Budidaya Tanaman Sela Berbasis Karet. Pusat Penelitian Karet. Balai Penelitian Sembawa.

Sardjono, M.A, T Djogo, HS Arifin, N Wijayanto. 2003. Bahan Ajar 2: Klasifikasi dan pola kombinasi komponen Agroforestri. World Agroforestry Centre (ICRAF) Southeast Asia. Bogor.

Setiawan. D.H \& A. Andoko. 2008. Petunjuk Lengkap Budidaya Karet. Agro Media. Jakarta.

Sudjadi. M \& Supriati. Y. 2001.Perbaikan Teknologi Produksi Kacang Tanah di Indonesia. Balai Penelitian Bioteknologi Tanaman Pangan. Bogor. http://biogen.litbang.deptan.go.id/terbita n/pdflagrobio_4_2_62-68.pdf

Tata, H.L. 2009. KiprahAgroforestri. Mikoriza:

KorporasiSalingMenguntungkanAntaraT anamandanJamur. World Agroforestry Centre (ICRAF) Southeast Asia. Bogor. 